Methods An exploratory, descriptive study that surveyed 65 individuals aged 18 or older was conducted. The survey asked questions about users' perceptions of their own feelings, the relationship between their affective state and their ability to navigate, the influence of the interface design, and whether their needs were satisfied by the information retrieved, among others, in order to identify users' affective states while dealing with the interface, to determine the level of satisfaction regarding its emotional design, and to learn what types of information users look for on the Department's home page.

Results Analysis of the data showed that of the users $67 \%$ presented a negative affective state in relation to the interface, while $33 \%$ were positive; $66.15 \%$ stated that their affective state interferes with their ability to navigate (for $33.85 \%$ it did not); $81.54 \%$ stated positive correlation between affective state and navigability; $80 \%$ were satisfied with the search and retrieval of information, $10 \%$ were dissatisfied, and $10 \%$ did not answer.

Conclusion Based on the principles of emotional design, the results shows that the design of the Department's home page had an impact on users' emotional states, which strengthens its role as an important tool in the prevention, treatment and improvement of the quality of life of the users.

\section{P4.004 ACTOR AND PARTNER EFFECTS OF RELATIONSHIP AND SEXUAL SATISFACTION ON EXTRA-MARITAL PARTNERSHIPS AMONG MARRIED COUPLES IN FISHING COMMUNITIES ON LAKE VICTORIA IN KISUMU COUNTY, KENYA}

doi:10.1136/sextrans-2013-051184.0903

'Z A Kwena, ${ }^{2}$ Mwanzo, 'E Bukusi, 'L Achiro, ${ }^{2} \mathrm{C}$ Shisanya. ${ }^{1}$ Kenya Medical Research Institute, Kisumu, Kenya; ${ }^{2}$ Kenyatta University, Nairobi, Kenya

Background Extra-marital partnerships have been associated with the spread of STIs including HIV among married couples. We sought to establish the actor and partner effects of relationship and sexual satisfactions on extra-marital partnerships among married couples. Methods We conducted a cross-sectional survey of 545 couples. We contacted a proportion to size simple random sample of fishermen on each beach as our index participants and asked them to enrol with their spouses. The consenting couples were separated into different private rooms for simultaneous gender-matched interviews. In addition to socio-economic and behavioural data, we collected information on extra-marital sex partners as well as the scores of participants on a 7 -item relationship satisfaction scale and 25 -item sexual satisfaction scale. We analysed data using multilevel modelling under the framework of actor-partner interdependent model (APIM).

Results Men had a median score of 56 (IOR 52-61) and women 53 (IOR 47-59) on sexual satisfaction scale. Both men and women had same median score of 16 (IOR 14-18) on relationship satisfaction scale. We found a significant partner effect of men's relationship satisfaction on their spouses number extra-marital partnerships such that the more men are satisfied in their relationship the fewer the number of extra-marital partners their spouses report $(B=-0.10$; $p=<0.01$ ). Similarly, we found a negative effect of men's sexual satisfaction on their own number of extra-marital partners $(B=-0.46 ; p=<0.01)$ and negative beta estimates for women $(B=-0.15 ; p<0.01)$ - meaning that if women are sexually satisfied, they report fewer number of extra-marital partnerships. Men's sexual satisfaction had a negative interaction with women's extra-marital partnerships $(B=-0.17 ; p=<0.01)$ such that the more sexually satisfied men are, the fewer the number of extra-marital partnerships their spouses report.

Conclusion Inculcating and maintaining good relationship and sexual satisfaction within couples in this community reduces their own and their partners' number of extra-marital partnerships.
P4.005 FROM POLICY TO PRACTICE: UTILIZING A HEALTH IN ALL POLICIES APPROACH TO ENHANCE PUBLIC HEALTH AND PROMOTE SEXUAL HEALTH IN COMMUNITIES AFFECTED BY STRUCTURAL CHANGE AND REDEVELOPMENT

doi:10.1136/sextrans-2013-051184.0904

${ }^{1} \mathbf{S} \mathbf{P}$ Williams, ${ }^{1} \mathrm{~K}$ Kroeger, ${ }^{2} \mathrm{H}$ Avey, ${ }^{3} \mathrm{E}$ Fuller, ${ }^{3} \mathrm{~J}$ Branscomb, ${ }^{4} \mathrm{~N}$ Wong. ${ }^{1}$ Centers for Disease Control and Prevention, Atlanta, GA, United States, ${ }^{2}$ Human Impact Partners, Oakland, CA, United States, ${ }^{3}$ Georgia Health Policy Center, Atlanta, GA, United States, 4Robert Wood Johnson Foundation, Princeton, NJ, United States

Background The international framework, Health in All Policies (HiAP), can operationalize approaches to enhancing health by strengthening links between health and policies from non-health sectors (i.e. transportation, land use). Redevelopment can stimulate changes in SDs and health outcomes. From 2010 onward, contiguous projects examined the how structural changes can affect health outcomes and STIs in an area with high STI morbidity.

Methods Fort McPherson, a 488-acre military base in Georgia that closed in 2011, served as the case study. Participatory and community engagement approaches included Health Impact Assessment (HIA), Photovoice, and community ethnographic assessment. First, the inclusion of health as a policy consideration in redevelopment was operationalized and a land zoning HIA was conducted. Project two determined what data, local policy, and sexual health opportunities existed in the "healthy community" conceptualization. Finally, we assessed community and provider perspectives about sexual health services and the potential impact of redevelopment on services.

Results The HIA yielded recommendations that addressed physical changes that would support the adoption of healthy choices, and facilitate social capital and cohesion. Photovoice helped residents recognise community assets that are threatened by SDs. Interactive area maps confirmed comorbidities of SDs and STIs. The ethnographic assessment identified service gaps and community members' perceptions of SD impacts, and recommendations of how community and sexual health can be improved.

Conclusions The projects demonstrated how HiAP can be operationalized to examine SD and health outcomes. Aggregated results determined that: (1) there are discrete "windows of opportunity" for incorporating health considerations into redevelopment decision-making; (2) the use of community and participatory engagement approaches can facilitate the systematic and now longitudinal observation of changing SD impact on STIs, and (3) communityidentified assets and policy opportunities can potentially mitigate SD's impact on health.

\section{P4.006 HIV, PSYCHOACTIVE SUBSTANCE USE AND ANXIETY: A STUDY OF THE DISCLOSURE FACTOR}

doi:10.1136/sextrans-2013-051184.0905

${ }^{1,2}$ M A Yunusa, ${ }^{1,2}$ A Obembe. 'Usmanu Danfodiyo University, Sokoto, Nigeria; ${ }^{2}$ Usmanu Danfodiyo University Teaching Hospital, Sokoto, Nigeria

Background The fear of disclosure remained a significant contribution to psychiatric morbidity among patients with HIV infection. This study aimed to determine which of the close associates did not know of the serostatus of the patients and how it influenced use of psychoactive substance and anxiety.

Method This was a prospective study among 159 patients with HIV infection attending outpatient clinic in of a teaching hospital in sokoto metropolis. They were interviewed using semi structured questionnaires which assessed individuals who were not aware of the serostatus of the patients and who patients would not want to be informed about their serostatus. Anxiety disorder was assessed using anxiety subscale of Hospital Anxiety and Depression Scale while CAGE questionnaire was used to assess for alcohol dependence state. Data obtained was analysed using SPSS for windows version 16.0. 